\title{
Deconstructing Doctoral Students' Socialization from an Institutional Logics Perspective: A Qualitative Study of the Socialization of Chinese Doctoral Students in Finland
}

\author{
Author: Gaoming Zheng \\ Institution: Tampere University \\ Email: gaoming.zheng@tuni.fi
}

For citation:

Zheng, G. (2019). Deconstructing Doctoral Students' Socialization from an Institutional Logics Perspective: A Qualitative Study of the Socialization of Chinese Doctoral Students in Finland. Frontiers of Education in China, 14(2), 206-233. doi:10.1007/s11516-019-0011-y

For online view-only full text:

https://rdcu.be/bIQJN. 


\begin{abstract}
While socialization has become a major lens of research in doctoral education, this paper advances the theoretical foundation of the socialization process in doctoral education by using the institutional logics theory. Specifically, it proposes an analytical framework for understanding the socialization of doctoral students, where it is seen as a process of reconciling different or even competing institutional logics that drive students' development in doctoral education. The framework has been applied in an empirical study of ten doctoral students in Finland who were funded by the China Scholarship Council (CSC). While proving the usefulness of the analytical framework, the study shows that CSC doctoral students mainly face the competing logics of profession and corporation during socialization. Influenced by a strong profession logic, the Chinese students have transformed themselves into novice professionals and knowledge producers. Corporation logic competed with profession logic in the management of doctoral students and has resulted in a lack of teaching experiences in doctoral training and a weak recognition of professional identity in the students' host universities. The influence of family logic, inherited from CSC doctoral students' cultural backgrounds, has been decoupled in the socialization process and has led to a strong sense of loss in handling the supervisory relationship between supervisors and students. Based on the findings of this study, the author provides several recommendations for host universities, supervisors, doctoral students, the CSC, and the Chinese Embassy in Finland to enable them to work together and help CSC doctoral students tackle the aforementioned challenges.
\end{abstract}

Keywords doctoral education, socialization, China, Finland, China Scholarship Council (CSC), institutional logics

\title{
Introduction
}

In the past two decades, there has been continuous interest in the socialization of doctoral students in order to enhance their future professional academic roles 
(e.g., Austin, 2002; Boden, Borrego, \& Newswander, 2011; Li \& Collins, 2014; Mendoza, 2007; Sweitzer, 2009; Szelényi, 2013; Weidman \& Stein, 2003; Wu, 2017). More recently, an update and conceptual expansion of socialization theory through the perspective of institutional logics (Mars, Bresonis, \& Szelényi, 2014) as well as a collection of key research findings concerning socialization and development in doctoral education (Gardner \& Mendoza, 2010) represent an increasing interest in the development of theory on this subject.

Since doctoral socialization is of great relevance to doctoral students' learning experiences and career development, understanding the process of socialization is significant for doctoral education. The present study continues in this tradition of research on doctoral education by exploring how and why the factors within the organizational context of socialization influence the process of socialization. Doctoral socialization can be defined as the process by which doctoral students develop an understanding of the norms, values, and practices of their disciplinary and professional field and acquire the social knowledge and skills necessary to assume their organizational roles (Gardner \& Mendoza, 2010; Mars et al., 2014). This definition looks at doctoral socialization on the organizational level rather than on an individual level (Gardner \& Mendoza, 2010). Doctoral socialization is also a process under the influence of certain interrelated factors concerning individual attitudes and abilities, the overall social and academic dynamics of a department, and the cultures of academic disciplines and higher education institutions (Solem, Lee, \& Schlemper, 2009; Weidman, 2010), as well as the recurrent themes and issues that underlie graduate education and influence the culture of academic disciplines and institutions (Weidman, Twale, \& Stein, 2001).

A robust line of research has documented the increased understanding of the impact of contextual factors on doctoral socialization (e.g., Gardner \& Mendoza, 2010; Mars et al., 2014; Solem et al., 2009; Sweitzer, 2009; Weidman, 2006; Weidman et al., 2001). Some scholars have examined the impact of the recurrent themes and issues in the context of higher education, such as academic capitalism (Mendoza, 2007; Szelényi, 2013) and national policy agendas (Mars et al., 2014). In a similar vein, scholars have examined the influence of factors related to individuals, higher education institutions, disciplinary and 
interdisciplinary culture, and academic communities (Boden et al., 2011; Li \& Collins, 2014; Pyhältö, Toom, Stubb, \& Lonka, 2012; Sakurai, Vekkaila, \& Pyhältö, 2017; Solem et al., 2009; Weidman et al., 2001). Such studies have primarily manifested the influence of socialization factors on the doctoral students' experiences. However, the literature fails to adequately capture the nature of these factors and does not explore the reasons behind their influences. Informed by such limitations in the literature, Mars et al. (2014) utilized the institutional logics approach to probe the institutional logics behind the factors that influence doctoral students in science and engineering. They defined these logics as market logic, scientific logic, and blended logic. Even though their study focused only on the market and regulative forces in the environment and neglected other possible influences, it nevertheless highlighted a path for the present study to follow. Thus, this study aims to narrow the research gap by utilizing the institutional logics perspective to examine the factors within the context of socialization and exploreing the way these factors have influenced the doctoral socialization process. The chosen theoretical perspective was a follow-up from Mars et al.'s (2014) achievement. It was determined based on the explanatory power of the institutional logics perspective in concretizing the institutional environmental factors and explaining the effect of environmental factors on the actors (Cai \& Mehari, 2015). Institutional logics are "the socially constructed, historical pattern of material practices, assumptions, values, beliefs, and rules by which individuals produce and reproduce their material subsistence, organize time and space, and provide meaning to their social reality" (Thornton \& Ocasio, 1999, p. 804).

This paper places a particular focus on how institutional logics in the context of socialization have influenced the socialization process of doctoral students in Finland who have been funded by the China Scholarship Council (CSC). This focus is particularly important when one considers that the number of Chinese doctoral students abroad has become a substantial demographic population of international doctoral students worldwide. Since the 1980s, China has become the world's largest sender of international doctoral students in the US, the UK and Australia (Shen \& Wang, 2019). Among Chinese doctoral students abroad, CSC doctoral students represent an important component, owing to the strategic 
significance of the CSC postgraduate scholarship scheme to train high-level talents and achieve national prosperity with science, education, and talents (Shen, 2018), and its continuing expansion of this population. In contrast to their large and fast-growing population, research concerning CSC doctoral students abroad has only received a moderate amount of attention. $\mathrm{Wu}$ (2017) and $\mathrm{Li}$ and Collins (2014) have analyzed the socialization experiences of Chinese doctoral students in Germany and America, respectively. These studies have highlighted the importance of researching Chinese doctoral students abroad in order to provide examples for studies concerning international doctoral students. They also suggested that a Chinese student's predispositions, inherited from Chinese culture and its educational system, can influence their socialization experiences (Li \& Collins, 2014; Wu, 2017). With a closer focus, Shen and his co-authors (Shen, 2018; Shen, Liu, \& Chen, 2017) have studied the learning experiences and productivity of CSC doctoral students in sandwich $\mathrm{PhD}$ programs. Their study indicated that the relationship with international host supervisors is critical to ensure that Chinese doctoral exchange students have successful learning experiences, higher levels of research productivity, and more international collaboration and networking. Currently, little is known about the socialization experiences of CSC doctoral degree students in general. Even less is known about CSC students in Finland, where collaboration with China in doctoral education has been flourishing since 2010 (Zheng \& Cai, 2018). Prior research concerning the dissimilarities and conflicts in the doctoral education system between China and Finland has also suggested more empirical studies are needed in order to explore the dynamics of these conflicts (Zheng, Kivistö, Shen, \& Cai, in press).

\section{Conceptual Framework}

The present research draws on the conceptual framework proposed by the author (Figure 1) which is grounded in the theoretical principles of both institutional 


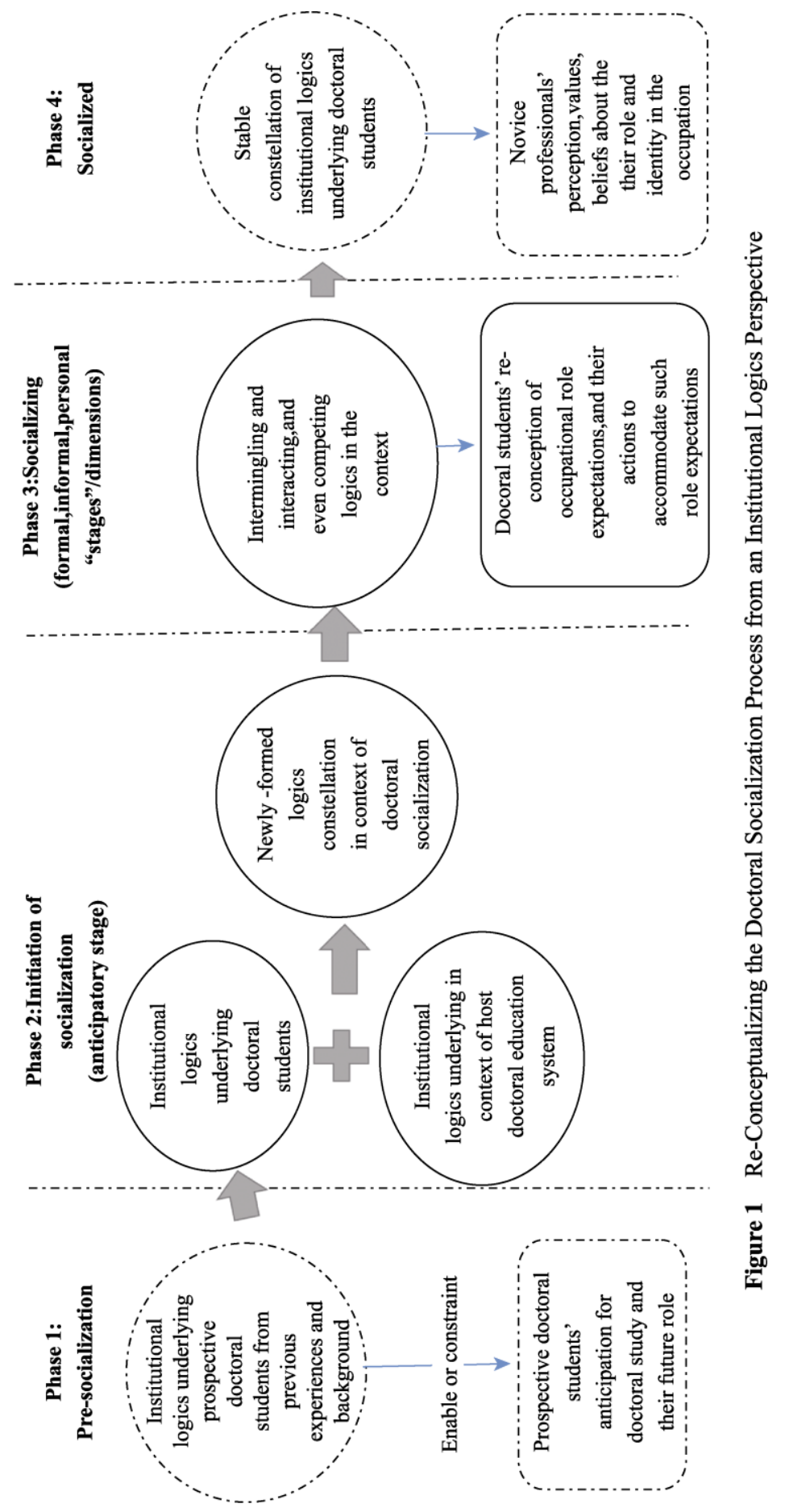


logics and graduate and professional student socialization. This framework represents the developmental path of individuals from prospective students to novice professionals (if socialized successfully) who are driven by the changes and interplays of institutional logics. Next, the author explains the theoretical principles and interpretations of the proposed framework.

\section{The Doctoral Socialization Process}

The socialization of professional graduate students (including doctoral students) is a continuous interactive process consisting of four stages-namely, the anticipatory stage, formal stage, informal stage, and personal stage (Austin, 2002; Weidman et al., 2001; Weidman \& Stein, 2003). Through reading the literature concerning these four stages (Weidman et al., 2001; Weidman \& Stein, 2003), the author found that except for the anticipatory stage, which is associated with prospective students and is well defined as the preparatory and recruitment phase (Weidman et al., 2001), the formal stage, informal stage, and personal stage are more dimensions of socialization rather than stages, and they can occur in a non-linear and even simultaneous fashion (Weidman \& Stein, 2003). The formal dimension emphasizes the compliance with the "formal instruction in the knowledge upon which future professionals authority will be based" (Weidman et al., 2001, p. 13), thus representing the regulative dimension of socialization. The informal dimension refers to the cultural and cognitive aspects of the socialization process, where doctoral students learn of the implicit "affective and cognitive dimensions of the professional roles" (Weidman \& Stein, 2003, p. 644) and accordingly adopt widely accepted and taken-for-granted behavior (Weidman et al., 2001). The personal dimension represents the normative dimension of socialization. In this dimension, students focus on professional matters and "learn how to accommodate the required normative dimensions of a role with his or her personal needs, attitudes and occupational role requirements" (Weidman et al., 2001, p. 15). These four stages encompass the entire development process of individuals moving from prospective doctoral students to their expected roles of doctoral students, academics, members of their discipline, and knowledge producers (Austin, 2002; Boden et al., 2011; Hakala, 2009; Mars 
et al., 2014; Weidman \& Stein, 2003).

\section{The Institutional Logics Perspective}

As a new strand of institutional analysis, the institutional logics perspective is considered a useful theoretical lens for studies of higher education (Bleiklie, Enders, \& Lepori, 2017; Cai \& Mehari, 2015; Lepori, 2016). It has also proven useful for understanding the organizational context of doctoral education (Gu \& Luo, 2016; Mars et al., 2014; Zheng, Cai, \& Ma, 2017; Zheng et al., in press; Zheng, Shen, \& Cai, 2018). The institutional logics approach posits that the interests, identities, values, and assumptions of individuals and organizations are embedded within prevailing institutional logics, thus enabling or constraining behavior and decision-making (Thornton \& Ocasio, 2008). Thornton and Ocasio (2008) also highlighted that the institutional logics perspective sees society as an inter-institutional system; this enables us to concretize any context as being potentially influenced by the institutional logics of different societal sectors. The deconstruction nature of institutional logics provides us with the possibility of theorizing the fragmented and even contradictory nature of factors in the context of doctoral socialization. Within socialization, environmental factors related to individual attitudes and abilities, the social and academic dynamics of a department, the cultures of academic disciplines and higher education institutions, and recurring issues in the field of higher education that affect disciplines and institutions are all subject to institutional logics in the doctoral education system on which they are based.

The deconstructive nature of institutional logics allows us to theorize the socialization process as a procedure of changing and interacting institutional logics. Structural overlap is an important mechanism that triggers these changes. When individual roles, organizational structures, and organizational functions that were previously distinct are forced into association, a structural overlap occurs and triggers the beginning of logics changes in institutions (Thornton, 2004). Because of this overlap of structures, institutional logics that align with individual roles and organizational structures and functions continue to intermingle, interact, and even compete with each other to exert influences on actors in the institution until they eventually reach a stable relationship (Thornton \& Ocasio, 2008). 
Based on the empirical discoveries of the doctoral education system in China and the ideal types of institutional logics developed by Thornton, Ocasio, and Lounsbury (2012), five institutional logics in the context of the doctoral education system - state logic, profession logic, family logic, market logic, and corporation logic have been identified and defined (Zheng et al., 2018). These logics are further examined and refined in the comparative study of the institutional logics of Finnish and Chinese doctoral education systems (Zheng et al., in press). Grounded in this, the author here presents definitions of the five logics in the context of doctoral education systems and uses them to interpret the context of doctoral socialization.

\section{State Logic}

In the state logic dimension of the doctoral education system, actors with bureaucratic power, such as state governments and university administrators, exert the greatest influence. The system is developed through government policies and regulations, routine administration, and the redistribution of resources. Doctoral education is regarded as a public good and represents the interests of the state and government.

\section{Profession Logic}

In the profession logic dimension of the doctoral education system, an individual's status rests on their personal expertise in disciplinary research. Doctoral supervisors who have more advanced expertise in the discipline and more respected academic reputations exert the most authority. Doctoral students, as apprentices of doctoral supervisors, try to enhance their personal expertise and enhance their status in the profession.

\section{Family Logic}

In the family logic dimension of the doctoral education system, a research family, which is comprised of a supervisor and their supervisees, becomes the basic unit 
of the system. A doctoral supervisor acts as the patriarchal leader of their supervision family, and supervisees become their academic children. The doctoral patriarchal leaders and their academic children behave like family members, and the relationship between them is based on patronage and reciprocity.

Market Logic

In the market logic dimension of the doctoral education system, market and market-like activities are adopted in the system and increase the competition for resources and cooperation within the industry. Doctoral degrees and doctoral graduates are profitable commodities and valuable assets in the academic market. The pursuit of a doctoral education is carried out along with a desired increase in the actors' profits.

\section{Corporation Logic}

In the corporation logic dimension of the doctoral education system, actors emphasize the efficiency of research resources, and performance-based management. On-time graduation, academic publications, and other activities that can demonstrate the effectiveness and efficiency of doctoral education management are encouraged. Doctoral students are managed through a contractual relationship in which universities or supervisors act as employers while doctoral students act as employees.

\section{Reconceptualizing Doctoral Socialization from the Institutional Logics Perspective}

Based on the theoretical principles of both graduate and professional student socialization and institutional logics, the author reconceptualized doctoral socialization as a process of different or even competing institutional logics that are inherited from an individual student's background, underlie the doctoral education system, and drive the student's development in doctoral education (Figure 1). Considering socialization as a dynamic and continuous process without a definite beginning or ending (Weidman et al., 2001), the proposed 
framework considers the phases before and after socialization. This aligns with Weidman et al.'s (2001) fundamental framework.

From left to right, the proposed framework begins with the pre-socialization phase: the time before doctoral socialization takes place. In this phase, prospective doctoral students' perceptions, values, and behavior are influenced by the multiple institutional logics in the institutional environment where they are located. When prospective students then enter the host doctoral education system and become doctoral students, they enter into the critical initiation of socialization phase. This phase also refers to the anticipatory stage of socialization. In this phase, the institutional logics embedded within doctoral students that were inherited from previous experiences and backgrounds have a structural overlap with the institutional logics in the context of the host doctoral education system. The logics from both sides then begin to intermingle and form a new institutional logics constellation that will guide the development of the doctoral students. At the point of structural overlap, doctoral students become aware of their new role expectations. After the structural overlap of the logics, those formed in the newly created constellation continue to intermingle and interact. Guided by this interaction, doctoral students learn of the regulative (formal), cultural-cognitive (informal), and normative dimensions of occupational role expectations, and accommodate their behavior to the expected role. The author identifies this phase as the socializing phase, which is in a state of constant change. It covers the formal, informal, and personal dimensions of socialization. Eventually, the doctoral students will either be successfully or unsuccessfully socialized when the relationship between multiple logics in the constellation reaches a stable and interactive status. Under the impact of such a logics constellation, doctoral students develop their professional identities.

Guided by the proposed framework, one can investigate doctoral students' socialization process and the driving forces behind the development and interaction of multiple logics in the logics constellation. These logics are inherited from (prospective) doctoral students' previous experiences and logics in the host doctoral education system. 


\section{Research Method}

Based on the belief that the socialization of CSC doctoral degree students in Finland is an uncharted area, the author considers a qualitative approach is appropriate for this study. Following the analytical framework, in 2017, the author collected empirical data through 11 semi-structured interviews and a thorough review of the relevant literature and reports.

In 2017, there were 97 CSC doctoral degree students in Finland. The author sent out interview invitations to them in May. 11 CSC students (five males and six females from five different universities) accepted the interview requests voluntarily and participated in the research in June and July. The response rate was $11.5 \%$. Unfortunately, however, one interview recording (male, social science) was broken due to recorder malfunction, so only ten interviews are valid. Each interview lasted between one and one and a half hours, with a focus on the students' anticipation of their doctoral education before beginning their doctoral studies, their perception of their doctoral study experiences, and their perception of their identities.

Ethical principles for scientific research in social sciences and humanities in Finland, i.e., voluntary participation and informed consent, avoiding harm, and protecting privacy (National Advisory Board on Research Ethics, 2009), have been taken into account in this study. After receiving the positive feedbacks from voluntary participants, the author further explained the usage of interview data and asked them for research permission, including permission for recording the interview. All interview participants agreed and sent their consent by signing a research consent form. The interviews were conducted anonymously, and the participants' information was kept confidential. To make them un-identifiable, the author labelled the interviewees, whose interviews were included into this study, from A1 to A10. Table 1 presents the basic information of labeled interviewees. Interviews were carried out in Chinese, the mother tongue of the participants, and were audio-recorded and later transcribed. The transcribed data were translated into English when direct quotations were used in this paper.

Table 1 Information of Interviewees 


\begin{tabular}{lllccll}
\hline Name & Discipline & Gender & $\begin{array}{c}\text { Start of } \\
\text { study year }\end{array}$ & $\begin{array}{c}\text { Funding period of } \\
\text { the CSC grant }\end{array}$ & $\begin{array}{c}\text { Means of } \\
\text { interview }\end{array}$ & Interview date \\
\hline A1 & $\begin{array}{l}\text { Chemistry } \\
\text { materials }\end{array}$ & Male & 2017 & $2017-2021$ & Face to face & Jun. 12, 2017 \\
A2 & Medicine & Female & 2017 & $2017-2021$ & Phone call & Jun. 12, 2017 \\
A3 & Education & Female & 2013 & $2013-2017$ & Face to face & Jun. 13, 2017 \\
A4 & Social science & Female & 2016 & $2017-2020$ & Face to face & Jun. 13, 2017 \\
A5 & Marine science & Male & 2017 & $2017-2021$ & Phone call & Jun. 14, 2017 \\
A6 & $\begin{array}{l}\text { Information } \\
\text { technology }\end{array}$ & Female & 2014 & $2015-2018$ & Phone call & Jun. 17, 2017 \\
A7 & Social science & Male & 2013 & $2013-2017$ & Phone call & Jun. 18, 2017 \\
A8 & Geology & Female & 2013 & $2013-2017$ & Face to face & Jun. 23, 2017 \\
A9 & Food science & Female & 2013 & $2013-2017$ & Phone call & Jun. 24, 2017 \\
A10 & Psycology & Male & 2014 & $2014-2018$ & Phone call & Jul. 9, 2017 \\
\hline
\end{tabular}

All the interviewees completed their master's degrees in China, and they came from diverse disciplines covering natural sciences, social sciences and medicine. The ratio of gender is 6:4 between female and male. They were completing their doctoral study in four different cities in Finland, including Helsinki, Jyvaskyla, Turku, and Oulu.

Besides interview data, documentary data covering the academic literature of doctoral student socialization and learning experiences in Finland and China, government and non-governmental association reports in relation to doctoral students in Finland were also analyzed.

The author analyzed the collected data through content analysis with the assistance of NVivo 10 software. The author first coded the collected data to the analytical framework and then used the five defined institutional logics of doctoral education systems to interpret the underlying logics of the coded content. The results of the analysis will be presented in the following section of this paper.

\section{Findings}

Guided by the proposed framework (Figure 1), in this section, the author first analyzes how the CSC doctoral degree students recalled their anticipation of their doctoral studies before entering the Finnish doctoral education system and 
interprets the logics behind this anticipation. The author then describes the institutional logics and related features of the Finnish doctoral education system and presents the components of the newly formed logics constellation in the initiation of the socialization process. The author then discusses how the logics constellation continues to develop, interact, and influence Finland's CSC doctoral degree students' experiences of socialization and development. The author concludes this section with an overview of certain features that CSC doctoral degree students have developed during socialization.

\section{Pre-Socialization: The Underlying Logics of CSC Doctoral Students' Anticipation of Doctoral Studies}

Analysis of the interview data shows that CSC doctoral students' preconceptions of doctoral education before socialization were aligned with their understanding of the doctoral education system in China. The Chinese doctoral education system features strong logics of state, profession, and family, and relatively weak but emerging market and corporation logics ( Zheng et al., 2018).

Interviewed CSC students recalled that they expected a strict quality assurance system for their doctoral studies. This expectation was driven by the Chinese state logic that emphasizes external regulation and assurance. The CSC PhD scholarship is supported in the form of state funding for doctoral education, and the prospective CSC doctoral degree students considered themselves stateselected, which also entails a logic of state. They also expected a closer, hierarchical, patron-like relationship with their supervisors and a stronger sense of belonging to their research family. For instance, interviewee A3 (female, education) stated, "In China, the supervisor-supervisee relationship is more hierarchical" and "I often placed myself in a humble position." She further explained, "Before I came, I thought there would be a research family or a closed research community in which we can communicate more with each other." Their pre-conceptions thus reflect a family logic. Regarding the training model, they believed that it would be similar to an apprenticeship, which indicates a logic of profession. Under the influence of market logic, some interviewees from the disciplines of science and engineering thought they would be used as academic labor for externally funded projects and be guided by their supervisors through 
the said projects. They also expected to publish articles in some publications during their doctoral studies; this manifests the impact of corporation logic on research productivity and efficiency.

\section{The Initiation of Socialization}

\section{Logics Underlying the Host Doctoral Education System in Finland}

Grounded in the strong Humboldt tradition of modern higher education, profession logic dominates the institutional environment of the Finnish doctoral education system, while corporation logic has been introduced to the system in recent decades and is growing fast. When compared to these two logics, the influence of state, family, and market logic are relatively weak (Zheng et al., in press).

Underlined by the profession logic, doctoral training is traditionally unstructured and in the form of a supervisor-supervisee apprenticeship with an emphasis on doctoral students' compatibility and initiative (Hakala, 2009). Doctoral students in Finland are treated primarily as junior academic professionals rather than students who need to be educated (Zheng et al. in press).

A logic of corporation is reflected in the performance-based management and employer management of doctoral students in Finland. Driven by corporation logic, a publication-based $\mathrm{PhD}$, which produces more publications for universities and allows supervisors to share their supervisory responsibility with referees (Hakala, 2009), has become increasingly popular. A publication-based dissertation is comprised of three to five peer reviewed articles published in international journals or books and an integrating summary. Meanwhile, some doctoral students are employed by universities for their doctoral research, thus introducing the employee practices of doctoral students. State logic in the Finnish doctoral system is rooted in the Nordic welfare-state model, where there is free tuition and universities enjoying sustainable autonomy in order to arrange doctoral training with an emphasis on equality (Hölttä, Jansson, \& Kivistö, 2010). Typically, the influence of state logic remains at the macro level, with loose regulations, financial incentives, and non-binding information steering (Zheng et al., in press). 
Similarly, influences of family logic and market logic are loosely enforced in the system. Family logic is usually only noticeable in some exceptional cases where supervisors and supervisees develop a close personal relationship based on reciprocity (Zheng et al., in press). Market logic can be observed in the increased competitiveness of external funding for Finnish universities (Hakala, 2009). Because of different funding situations, doctoral students are categorized into different groups (e.g., employed doctoral students with paid university positions, project-funded $\mathrm{PhD}$ students who are financially supported by external project funding, doctoral students who receive external grants from foundations, self-paid doctoral students with their own funding). The CSC doctoral degree students belong to the third group in Finland (i.e., doctoral students who receive external grants from foundations).

\section{Structural Overlap and Newly Formed Logics Constellation}

When the CSC doctoral students were enrolled in the Finnish doctoral education system, they formed an association with the underlying logics of the Finnish doctoral education system. As shown in Figure 2, the components of the logics underlying the CSC doctoral students' anticipations and the logics of the Finnish doctoral education system are the same. They comprise the context of doctoral socialization and form a logics constellation of profession, corporation, state, family, and market. These logics guide the socialization of CSC doctoral students. 


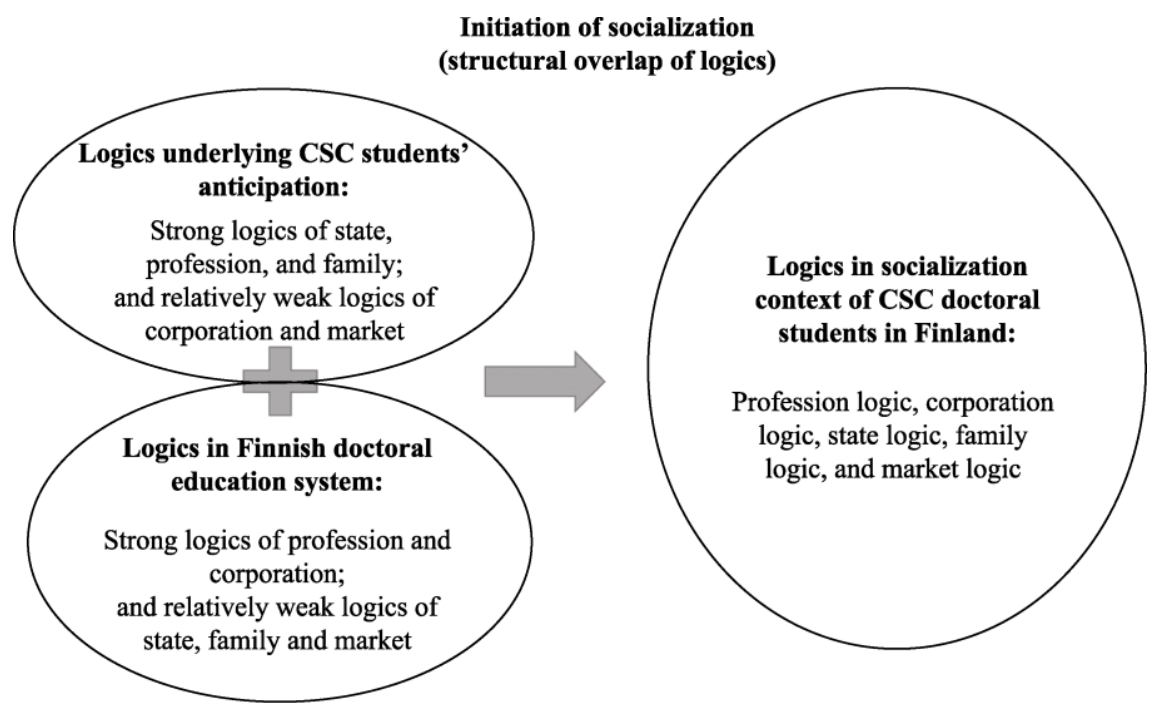

Figure 2 Structural Overlap and Newly Formed Logics Constellation at the Initiation of Socialization

Nevertheless, we can also see that the interrelations and influences of multiple logics are different to quite a large extent (Figure 2). This will affect the interactions among logics in the newly formed logics constellation. Common ground can be found in the strong profession logic as well as the relatively weak market logic, while the situation of the other three logics (i.e., family logic, state logic, and corporation logic) is relatively different. When it comes to a specific aspect (i.e., the supervisory relationship), the underlying logics can also be different.

\section{Socializing Phase}

\section{The Developmental Trend of Intermingling Logics}

Since the initiation, multiple logics in the newly formed logics constellation continue to intermingle, guide the CSC doctoral students' development, and affect their experiences in the socializing phase. In this section, the author explores how CSC doctoral students perceive doctoral education and their current roles within this education. The changes in terms of the logics underlying 
their conceptions are also explored. The analysis shows profession logic and corporation logic have been strengthened, while state logic and family logic have been weakened. No significant change is observed in relation to market logic.

First, CSC doctoral students in Finland have learnt of the formal, informal, and normative expectations of their role as academic researchers and have acted accordingly. Such findings suggest the strengthening of profession logic in the students' perceptions and behavior. The interviewees said that they learnt from their supervisors' professionalism and rigorousness in relation to scientific research, and they gradually understood how to conduct proper research and be independent researchers. They also became aware of the importance of academic autonomy and freedom, and thus appreciated the advantage of the CSC scholarship. According to interviewee A4 (female, social science), "With the benefit from the grant, I can almost completely concentrate on my doctoral research without any interruptions and disturbance." Similarly, interviewee A6 (female, information technology) said she valued the freedom of being able to say no. "I am more confident to reject some project tasks if I don't want to [do them]. If it is related to my doctoral research, I will do it. If not, I refuse."

Second, the CSC doctoral students' preferences for publication-based dissertations and their awareness of appropriate employee behavior are driven by corporation logic. All interviewees were completing a publication-based dissertation. The interviewees realized that due to their "unemployed" status, their supervisors and other actors believed it neither right nor legal to involve them in any activities other than doctoral research. As a result, most of them were uninvolved in teaching or management activities during their studies. According to interviewee A10 (male, phycology): "Because I am not a university employee, in my supervisor's opinion, the funding for my doctoral study is solely for doctoral research." Employer behavior was also noted in terms of ensuring the well-being of the doctoral students. For instance, interviewee A9 (female, food science) was injured during a business trip:

The faculty agreed it was an injury at work. If I were employed by the university, the university's occupational insurance company could have covered the cost. ... The faculty administrator would like to help, but it is the system that she cannot change. 
Some interviewees tried to fight against this differentiated treatment at the beginning of their doctoral study, but they gradually compromised. Some even rationalized and fully accepted it. This suggests that corporation logic was rather strong and changed their conceptions. As interviewee A3 (female, education) put it:

Probably I (should) consider myself as a student. I am studying instead of working. Otherwise, I would think it is an unfair situation considering the nature of work done by me is the same as that by other positioned $\mathrm{PhD}$ students.

Third, CSC doctoral students became more independent and less reliant on external steering in the Finnish system. This shows the influence of state logic, as external regulation has been weakened. However, its influence has been shown to be strengthened in the supervisory relationship, and it encouraged the students to develop an equal relationship with their supervisors. When asked about the relationship with their supervisors, all of the interviewees said that it was equal and collegial.

Fourth, the influence of family logic was weakened in the socializing phase. Most of the interviewees had not developed a close and personal supervisory relationship. Their distant relationship sometimes was described by interviewees (e.g., interviewee A5, male, marine science) as a lack of caring, "Sometimes I feel there's no connection between my supervisor and me. My supervisor treats me equally as a colleague. However, equality doesn't mean caring." Only in one case (interviewee A4, female, social science) was the influence of family logic so strong that her supervisory relationship become close and familial as a result. Interviewee A4 described her supervisor:

Except for academic matters, we are also close, actually even closer, in daily life. I have connections with his family. He cares about me, not only regarding the academic aspect, but also my life in Finland. ...I think comparing to supervisory relationship in China, our relation is still less close, but, comparing to the normal supervisory relation in Finland, it is closer. 
Their close relationship also represents reciprocity. A4 admitted she has voluntarily helped her supervisor deal with some "small" tasks, e.g., email communication with Chinese partners, but she felt she owed more to her supervisor's help and caring. As A4 explained, "I think supervisor-supervisee relationship basically is a relationship between human beings. When you give others a favor, they would also possibly return you one." Her thinking as well as her relation with her supervisor entails a strong logic of family.

Lastly, the change of market logic was not significant, as interviewees from the fields of natural science and engineering mentioned that they witnessed market-like behavior in their research group, as expected, which affirmed their beliefs in academic capitalism. However, the students also mentioned that they preferred to have their articles published in international indexed journals in order to meet the needs of the academic market. This preference is aligned with the global trend of marketization and may imply a slight strengthening of this logic.

\section{Relation and Conflicts of Intermingling Logics}

Following the changing logics, profession and corporation logics have both been strengthened and found to be competing for the domination of the socialization context. This finding is based on the analysis of interview data. Enforced by the strong profession logic, CSC doctoral students have adapted their academic values and gained recognition as junior professionals in an international academic community as well as in their disciplinary field. They usually write at least three refereed publications during their doctoral studies, thus proving their active research productivity. However, the corporation logic competed with and decoupled the influence of profession logic in the recognition of their professional identities and personal expertise development. Due to the employment-oriented way in which Finnish universities manage doctoral students, the CSC doctoral students who do not behave as employees have been marginalized in the management system. The interviewees felt that their professional identities as junior professionals and their academic contributions were not recognized by their universities. Most interviewees considered themselves to be only students rather than independent researchers in their 
universities. As they were usually only involved in activities related to their doctoral research, they had scant opportunity to develop their teaching expertise. From time to time, the interviewees questioned the rationale behind the employment-oriented practices in managing doctoral students and argued that doctoral students should be treated equally by universities, regardless of their employment status. For instance, Interviewee A10 (male, phycology) pointed out:

The nature of our work (doctoral students with grants and positioned doctoral students) is the same. The quality of our work is not different, but we are not treated equally. I think this is something we should change. Here I'm not referring to the payment differences, but the identity differences, and the discrepancy of expected equal functional role and unequal identity recognition.

This implies that profession logic can be competitive and decouple the influence of corporation logic in the management of doctoral students.

Aside from the competition between profession and corporation logics, decoupling occurs between state and family logics, and meanwhile between profession and family logics. The weakening of family logic in the socializing phase implies that the influence of the said logic has been decoupled by the other two logics of state and profession. As a result, instead of developing a hierarchical patron-based relationship, CSC doctoral students establish an equal relationship with their supervisors. Instead of developing a close and informal relationship, they establish a formal and professional relationship with their supervisors. However, when the embedded family logic held by CSC doctoral students is strong, the opposite could happen. Under such continuous tension between logics, the CSC doctoral students often felt a sense of loss in handling their supervisory relationship. For instance, A3 (female, education) mentioned, "Sometimes I don't know how to deal with my supervisor, because it is so different here. They are more equal. Sometimes they make jokes with me as well." Similarly, A5 (male, marine science) found himself confused about the supervisory relationship. Because in China he had a close relation with his supervisor and his supervisor took care of him as a family member, when in Finland his relation with supervisors become more formal, he often felt confused: 
Sometimes I feel he doesn't care about me. But if I said so, it is not true because I am his student and he still supervises me. But if I said he cares about me, he never asks about my progress. ...Until now, I still haven't figured out what is the best way to get along with my supervisor.

In comparison with competition and decoupling, market logic is found to be less dominant and competitive and only exerts its influence on CSC doctoral students in certain ways (e.g., enforcing market-like values and behavior in publishing and project activities).

\section{Socialization}

Gradually, in the context of doctoral socialization, while the gradually strengthening profession and corporation logics compete for dominance, the influence of family logic weakens as it becomes decoupled by the logics of profession and state. Market logic does not dispute the dominant logics, but rather combines with them and exerts its influence in a different way. This logics constellation is changing and interacting in a relatively stable way. Under the influence of the said constellation, CSC doctoral students develop their professional identities as novice professionals. In the socialization process, they also develop certain unique features: (1) They have acquired the research expertise required for competent researchers. However, they usually possess insufficient teaching experience. (2) They have developed a more equal and formal relationship with their supervisors, but feel a sense of loss in handling this supervisory relationship. (3) They have become productive knowledge producers. (4) With their research competency and productivity, they become recognized as novice professionals in their disciplines. However, in their universities, there is poor recognition of their professional identities. Thus, as novice academic professionals, they are more committed to the discipline than to their respective institutions. 


\section{Discussion}

This study makes an important contribution to the body of research that examines the factors that influence the development and socialization experiences of doctoral students. Particularly, it helps us better understand why doctoral students are socialized or not socialized in a certain way. For instance, even though previous studies have indicated that doctoral students with external funding in Finland usually lack teaching experience (Hakala, 2009), few studies have explained the reasons behind this. From the present empirical study, and using its analytical framework, we can see that the main reason may lie in that the corporation logic of the management of doctoral students limits the scope of activities of students with external funding and without contractual relationship.

Meanwhile, this study affirms that socialization is a by-directional process that occurs between individual students and the host doctoral education system (Mars et al., 2014). By "by-directional process," it means that the context of the doctoral education system influences the students; in turn, the system itself is possibly influenced by the students' values and beliefs that they inherited from previous experiences (Austin, 2002). Furthermore, the study proposes its conceptual framework to consider the interactions of the by-directional influences. To date, most research within this field of inquiry has studied only one-directional influence, i.e., either the influences of individuals' previous experiences and cultural backgrounds or the contextual factors of the host doctoral education system. Previous studies have failed to capture the common nature of these influential factors, their relations and interactions, and the influences related to said relations and interactions. This is an important gap in the extant literature that the present study contributes to filling.

The proposed analytical framework is particularly useful for understanding the socialization of international doctoral students due to its explanatory power of the natural cultural differences between individuals and the host system, but it also leads us to be conscious of the interpretation of societal institutional logics in different cultural contexts. Today, the predominant educational approaches come from the West, even in non-Western contexts (Grigorenko, 2013). This means that the interpretation of ideal institutional logics is based on a Western perspective (Thornton et al., 2012). However, the adoption of the Western model 
in a non-Western context does not simply result in a mono-cultural system of university management being applied to a non-Western context. Instead, this system can integrate with the traditional culture of the non-Western context and develop its own by- or multi-culturalism (Yang, 2017). Even with the same societal logic, its reflection may be divergent in different societal contexts. Hence, when applying and interpreting institutional logics in different contexts, one should carefully consider the contextual societal realities and cultural traditions. Further research can also be done to investigate and redefine institutional logics in a more multicultural society (e.g., a Western-Confucian society).

The empirical findings of this study suggest that the dominant logics (i.e., profession and corporation) are the most influential logics in terms of the CSC doctoral students' experiences and development. Profession and corporation logics represent the core foundations of the Finnish doctoral education system, which is primarily anchored in the recurring themes of professionalism and new public management in higher education. The importance of professionalism is easy to understand, since doctoral education, as a preparatory passage for future scholars, by nature indicates the trend of professionalism. New public management was formally introduced to university management in Finland with the University Act of 2010 (Broucker, de Wit, \& Leisyte, 2015). This act heralded an entrepreneurial culture for Finnish universities by separating Finnish universities from the state-budgeting bureaucracy and transforming them into independent corporations under public law or foundations under private law (Zheng et al., in press). Along with these characteristics, contractual relationships, performance-based funding, and emphasis on efficiency and other corporate behavior intensify the management nature of Finnish doctoral training. The findings of this study are anchored in the current ongoing transformation of Finnish higher education with the University Act of 2010, and support Weidman et al.'s (2001) argument that doctoral socialization should not be considered in an encapsulated institutional environment, but rather in consideration of the recurring themes and issues of higher education systems.

Findings in the study highlight the importance of understanding cultural differences, complementing what $\mathrm{Li}$ and Collins (2014) have indicated about the limitations of Weidman et al.'s (2001) socialization framework in explaining the 
discrepancy of cultures. For instance, in this study, some interviewed students mentioned feelings of aloneness within the scholarly community of the university. Some reported feeling lost when handling their supervisory relationship. They are, as explained earlier, associated with strong family logic in their preconceptions inherited from the traditional familial culture of the Chinese educational system, where teachers are respected as parents or patriarchal leaders (Gu, 2004). This is different from the erosion of the role of the extended family as the basic societal unit in Finnish society, where an emphasis on individualism has to a certain extent replaced the role of the family (Zheng et al., in press). This individualism eliminates or minimizes the influence of family logic on the Finnish doctoral education system. By understanding the logic that underlies a certain culture (e.g., family logics underlying family culture) and its interaction with other logics inherited from other cultures, such findings have contributed to distinguishing and concretizing cultural differences and their associated influences in doctoral students' socialization context. The study also supports previous studies that the influences of traditional Chinese culture should be taken into account when exploring the socialization experiences of doctoral students from China (Wu, 2017; Li \& Collins, 2014).

\section{Conclusion}

This study contributes to the theoretical understandings of socialization theory and makes empirical discoveries as to CSC doctoral degree students' socialization experiences in Finland. Interpreting the underling logics behind the influential factors affecting doctoral students' socialization, this study examines the true forces behind the factors related to both individual values and predispositions and those of the host doctoral education system, and consider them within the same theoretical framework. Through this, the proposed framework can help us better understand the reasons behind the success and failure of quality assurance of doctoral education, i.e. why some doctoral students are socialized or not socialized in a certain way. In future studies, researchers can consider applying the proposed analytical framework to different contexts and further refine it. 
The empirical study, guided by the proposed framework, has not only proven the usefulness of the said framework, but also clarified the socialization experiences of CSC doctoral students in Finland and the logics behind those experiences. As the analysis results show, along with the development and interaction of the logics of profession, corporation, state, family, and market, CSC doctoral students in Finland have successfully developed into knowledge producers and junior professionals who are recognized by their discipline and academic community. They also face multiple challenges, such as a lack of professional identity recognition in host universities and the insufficient development of teaching expertise, due to the influence of the competing logics of profession and corporation, and a sense of loss in the supervisory relationship, driven by the continuous tension between family and state logics, as well as between family and profession logics. Nevertheless, considering that the sample in this study includes just ten CSC doctoral degrees students, more empirical studies should be carried out in the future in order to further examine the findings of this study.

By drawing on the findings in order to tackle the aforementioned challenges, we should first strengthen the influence of profession logic in the management of doctoral students and promote the idea of doctoral students being treated as equals. Universities need to recognize the position of CSC doctoral students as grant doctoral students and their identities as researchers in the same way that employed doctoral students are. In relation to this, universities should also provide more pedagogical training and teaching practices to doctoral students and enhance their teaching expertise.

Secondly, by learning from the case of interviewee A4, the sense of loss experienced by the students could be resolved by strengthening the family logic in the supervisory relationship. When supervising CSC doctoral students, supervisors are recommended to account for cultural differences and try to understand the needs and anticipations of CSC students. They are encouraged to take more initiatives in following the progress of the students' doctoral research and involve the students in the local academic community more proactively. This will not only enhance the mutual understanding and trust between supervisor and supervisee (thus resolving the sense of loss), but also increase the sense of 
belonging and commitment of students to their host universities.

Thirdly, by being armed with an understanding of the institutional logics behind the challenges faced by the CSC doctoral students, they themselves can proactively take action to change the institutional logics in their institutional environment. For instance, similar to the suggestion for supervisors, doctoral students could also increase the influence of family logic in their supervisory relationship. They could also follow the culture of strong associations and profession logic in Finland by forming their own association in their local community. By forming an association to represent CSC doctoral students, the recognition of their professional identities in the local academic community can become more visible. A shared association can also provide a common platform for CSC doctoral students to share their experiences and create a sense of belongingness.

Fourthly, as state logic exerts a strong influence on prospective CSC doctoral students' preconceptions, the said logic can help them transition smoothly from the Chinese education system to the Finnish doctoral education system. The CSC and the Chinese Embassy in Finland are recommended to provide more information packages and practical guidance about the Finnish doctoral education system to prospective CSC doctoral students. By gaining more knowledge about the host doctoral education system before socialization, CSC doctoral students can better align their preconceptions with their future host system and reduce the conflicts regarding logics in the initial phase of doctoral socialization.

\section{References}

Austin, A. E. (2002). Preparing the next generation of faculty: Graduate school as socialization to the academic career. The Journal of Higher Education, 73(1), 94-122. doi: 10.1353/jhe.2002.0001

Bleiklie, I., Enders, J., \& Lepori, B. (2017). Organizational configuration organizational configurations of modern universities, institutional logics and public policies-towards an integrative framework. In I. Bleiklie, J. Enders, \& B. Lepori (Eds.), Managing universities: Policy and organizational change from a Western European comparative perspective (pp. 303-326). London, UK: Palgrave Macmillan. 
Boden, D., Borrego, M., \& Newswander, L. K. (2011). Student socialization in interdisciplinary doctoral education. Higher Education, 62(6), 741-755. doi: $10.2307 / 41477900$

Broucker, B., de Wit, K., \& Leisyte, L. (2015). An evaluation of new public management in higher education. Paper presented at the EAIR. Krems, Austria

Cai, Y., \& Mehari, Y. (2015). The use of institutional theory in higher education research. In J. Huisman \& M. Tight (Eds.), Theory and method in higher education research III (pp. 1-25). Bingley, UK: Emerald.

Gardner, S. K., \& Mendoza, P. (2010). On becoming a scholar: Socialization and development in doctoral education (1st ed.). Sterling, VA: Stylus.

Grigorenko, E. (2013). Hitting, missing, and in between: A typology of the impacts of Western education on the non-Western world. In J. Elliott \& E. Grigorenko (Eds.), Western psychological and educational theory in diverse contexts (pp. 165-186). London and New York: Routledge.

Gu, J., \& Luo, Y. (2016). 学术抑或市场: 博士生培养模式变革的逻辑与路径 [Academic or market: The logic and paths of doctoral training pattern reform]. 高等教育研究 [Journal of Higher Education], 37(1), 49-56.

Gu，M. Y (2004). 中国教育的文化基础 [Cultural foundations of Chinese education]. Taiyuan, China: Shanxi Education Press.

Hakala, J. (2009). Socialization of junior researchers in new academic research environments: Two case studies from Finland. Studies in Higher Education, 34(5), 501-516. doi: $10.1080 / 03075070802597119$

Hölttä, S., Jansson, T., \& Kivistö, J. (2010). Emerging markets in the Finnish system. In R. Brown (Ed.), Higher education and the market (pp. 123-134). New York and Oxon: Routledge.

Lepori, B. (2016). Universities as hybrids: Applications of institutional logics theory to higher education. In J. Huisman \& M. Tight (Eds.), Theory and method in higher education research (pp. 245-264). Bingley, UK: Emerald.

Li, W., \& Collins, C. S. (2014). Chinese doctoral student socialization in the United States: A qualitative study. Forum for International Research in Education, 1(2), 32-57. doi: 10.18275/fire201401021012

Mars, M. M., Bresonis, K., \& Szelényi, K. (2014). Science and engineering doctoral student socialization, logics, and the national economic agenda: Alignment or disconnect? Minerva, 52(3), 351-379. doi: 10.1007/s11024-014-9256-Z

Mendoza, P. (2007). Academic capitalism and doctoral student socialization: A case study. The Journal of Higher Education, 78(1), 71-96. doi: 10.1080/00221546.2007.11778964

National Advisory Board on Research Ethics. (2009). Ethical principles of research in the humanities and social and behavioural sciences and proposals for ethical review. Retrieved from https://www.tenk.fi/sites/tenk.fi/files/ethicalprinciples.pdf 
Pyhältö, K., Toom, A., Stubb, J., \& Lonka, K. (2012). Challenges of becoming a scholar: A study of doctoral students' problems and well-being. ISRN Education, 12. doi: $10.5402 / 2012 / 934941$

Sakurai, Y., Vekkaila, J., \& Pyhältö, K. (2017). More or less engaged in doctoral studies? Domestic and international students' satisfaction and motivation for doctoral studies in Finland. Research in Comparative and International Education, 12(2), 143-159. doi: $10.1177 / 1745499917711543$

Shen, W. (2018). Transnational research training: Chinese visiting doctoral students overseas and their host supervisors. Higher Education Quarterly, 72(3), 224-236. doi: 10.1111/hequ. 12168

Shen, W., Liu, D., \& Chen, H. (2017). Chinese PhD students on exchange in European Union countries: Experiences and benefits. European Journal of Higher Education, 7(3), 322-335. doi: 10.1080/21568235.2017.1290885

Shen, W., \& Wang, C. (2018). Historical trends in Ph.D. study abroad and their implications for transforming the Chinese higher education system. In A. V. Oleksiyenko, Q. Zha, I. Chirikov, \& J. Li (Eds.), International stutus anxiety and higher education: The soviet legacy in China \& Russia (1st ed., vol. 35, pp. 309-333). Hong Kong, China: Springer \& Comparative Education Research Centre.

Solem, M., Lee, J., \& Schlemper, B. (2009). Departmental climate and student experiences in graduate geography programs. Research in Higher Education, 50(3), 268-292. doi: $10.1007 / \mathrm{s} 11162-008-9117-4$

Sweitzer, V. (2009). Towards a theory of doctoral student professional identity development: A developmental networks approach. The Journal of Higher Education, 80(1), 1-33. doi: $10.1080 / 00221546.2009 .11772128$

Szelényi, K. (2013). The meaning of money in the socialization of science and engineering doctoral students: Nurturing the next generation of academic capitalists? The Journal of Higher Education, 84(2), 266-294. doi: 10.1080/00221546.2013.11777288

Thornton, P. H. (2004). Markets from culture: Institutional logics and organizational decisions in higher education publishing. Stanford, CA: Stanford Business Books.

Thornton, P. H., \& Ocasio, W. (1999). Institutional logics and the historical contingency of power in organizations: Executive succession in the higher education publishing industry, 1958-1990. American Journal of Sociology, 105(3), 801-843. doi: 10.1086/210361

Thornton, P. H., \& Ocasio, W. (2008). Institutional logics. In R. Greenwood, C. Oliver, R. Suddaby, \& K. Sahlin-Andersson (Eds.), The Sage handbook of organizational institutionalism (1st ed.) (pp. 99-129). Los Angeles, London, New Dehli, Singapore: Sage Publications.

Thornton, P. H., Ocasio, W., \& Lounsbury, M. (2012). The institutional logics perspective: A new approach to culture, structure and process. New York, NY: Oxford University Press. 
Weidman, J. C. (2006). Socialization of students in higher education: Organizational perspectives. In C. C. S. Conrad \& C. Ronald (Eds.), The Sage handbook for research in education: Engaging ideas and enriching inquiry (pp. 253-262). Thousand Oaks, London, New Delhi: Sage Publications.

Weidman, J. C. (2010). Doctoral student socialization for research. In S. K. Gardner \& P. Mendoza (Eds.), On becoming a scholar: Socialization and development in doctoral education (pp. 45-55). Sterling, VA: Stylus Publishing.

Weidman, J. C., \& Stein, E. L. (2003). Socialization of doctoral students to academic norms. Research in Higher Education, 44(6), 641-656. doi: 10.1023/A:1026123508335

Weidman, J. C., Twale, D., \& Stein, E. L. (2001). Socialization of graduate and professional students in higher education: A Perilous passage? ASHE-ERIC Higher Education Report, 28(3).

$\mathrm{Wu}$, R. (2017). Academic socialization of Chinese doctoral students in Germany: Identification, interaction and motivation. European Journal of Higher Education, 7(3), 276-290. doi: 10.1080/21568235.2017.1290880

Yang, R. (2017). The cultural mission of China's elite universities: Examples from Peking and Tsinghua. Studies in Higher Education, 42(10), 1825-1838. doi: 10.1080/03075079.2017.1376873

Zheng, G., \& Cai, Y. (2018). Collaboration between Europe and China in doctoral education: Historical development and future challenges. In A. V. Oleksiyenko, Q. Zha, I. Chirikov, \& J. Li (Eds.), International status anxiety and higher education: Soviet legacy in China and Russia (1st ed., vol. 35, pp. 335-361). Hong Kong, China: Springer \& Comparative Education Research Centre.

Zheng, G., Cai, Y., \& Ma, S. (2017). Towards an analytical framework for understanding the development of a quality assurance system in an international joint programme. European Journal of Higher Education, 7(3), 243-260. doi: 10.1080/21568235.2017.1290877

Zheng, G., Kivistö, J., Shen, W., \& Cai, Y. (in press). Comparing doctoral education in China and Finland: An institutional logics perspective In H. Liu, F. Dervin, \& X. Du (Eds.), Nordic-Chinese intersections within education. Helsinki, Finland: Palgrave MacMillan.

Zheng, G., Shen, W., \& Cai, Y. (2018). Institutional logics of Chinese doctoral education system. Higher Education, 76(5), 753-770. doi: 10.1007/s10734-018-0236-3 